(9) (1) https://creativecommons.org/licenses/by/4.0/

ARTIGO

\title{
A EDUCAÇÃO DE SURDOS NO SÉCULO XIX E A CIRCULAÇÃO DA LÍNGUA DE SINAIS NO IMPERIAL INSTITUTO DE SURDOS-MUDOS
}

\author{
ANGÉLICA NIERO MENDES DOS SANTOS ${ }^{1}$ \\ ORCID: https://orcid.org/0000-0001-8451-6386 \\ CÁSSIA GECIAUSKAS SOFIATO ${ }^{2}$ \\ ORCID: http://orcid.org/0000-0001-52919658
}

\begin{abstract}
RESUMO: Este artigo objetiva compreender a educação de surdos no século XIX e como se dava a circulação da língua de sinais no Imperial Instituto de Surdos-Mudos, no referido período. O Imperial Instituto de Surdos-Mudos foi fundado em 1857 para a educação de surdos no Brasil e para um trabalho de reabilitação. O estudo empreendido trata-se de uma pesquisa ${ }^{3}$ documental e bibliográfica de natureza qualitativa. A coleta de dados foi realizada em fontes primárias, tais como: Relatórios dos Ministros e Secretários de Estado dos Negócios do Império e Relatórios dos diretores do Imperial Instituto dos Surdos-Mudos. Como resultados, encontramos evidências de que a língua de sinais circulava na instituição e estava presente nas relações que se estabeleciam entre professores e alunos. Entretanto, tal língua não aparecia no currículo prescrito da instituição, em função do oralismo.
\end{abstract}

Palavras-chave: Educação de surdos, Império do Brasil, Língua de sinais.

\section{DEAF EDUCATION IN THE $19^{\text {TH }}$ CENTURY AND SIGN LANGUAGE CIRCULATION IN THE IMPERIAL INSTITUTE FOR DEAF-MUTES}

\begin{abstract}
This article aims to understand the education of deaf people in the $19^{\text {th }}$ century in Brazil and describe the circulation of sign language at the Imperial Institute of Deaf-Mutes during that period. The Imperial Institute for Deaf-Mutes was founded in 1857 to educate deaf people in Brazil and for rehabilitation work. This study is a qualitative documentary and bibliographical research. Data were collected from primary sources, including Reports from Ministers and State Secretaries of the Empire and from the Directors of the Imperial Institute for Deaf-Mutes. We found evidences that sign language circulated at the institution and was present in teacher-student relationships. However, it did not appear in the institution's prescribed curriculum, due to oralism.
\end{abstract}

Keywords: Deaf education, Brazilian Empire, Sign language.

\section{LA EDUCACIÓN PARA SORDOS EN EL SIGLO XIX Y LA CIRCULACIÓN DE LA LENGUA DE SEÑAS EN EL INSTITUTO IMPERIAL DE SORDOMUDOS}

\footnotetext{
${ }^{1}$ Mestre em Educação pela Universidade de São Paulo. São Paulo, SP, Brasil. <angelica.niero@gmail.com.br>.

${ }^{2}$ Docente da Faculdade de Educação da Universidade de São Paulo. São Paulo, SP, Brasil. < cassiasofiatol@gmail.com.br> .

${ }^{3}$ A pesquisa em questão contou com o financiamento do Conselho Nacional de Desenvolvimento Científico e Tecnológico (CNPq).
} 
RESUMEN: Este artículo tiene como objetivo comprender la educación de las personas sordas en el siglo XIX y cómo fue la circulación de la lengua de señas en el Instituto Imperial de Sordomudos en ese período. El Instituto Imperial de Sordomudos fue fundado en 1857 para la educación de personas sordas en Brasil y para un trabajo de rehabilitación. El estudio realizado es una investigación documental y bibliográfica de carácter cualitativo. Los datos fueron recolectados de fuentes primarias, como: Informes de los Ministros y Secretarios de Estado de Negocios del Imperio e Informes de los Directores del Instituto Imperial de Sordomudos. Como resultado, encontramos evidencias de que la lengua de señas circulaba en la institución y estaba presente en las relaciones que se establecían entre maestros y estudiantes. Sin embargo, la lengua de señas no aparecía en el plan de estudios prescrito de la institución debido al oralismo.

Palabras clave: Educación de sordos, Imperio de Brasil, lengua de señas.

\section{INTRODUÇÃO}

O desenvolvimento da educação de surdos no período Imperial no Brasil, especificamente no Segundo Reinado, ainda suscita muitos questionamentos devido às suas variantes e tentativas de estabelecimento de um projeto educacional especializado, alinhado com o projeto de instrução escolar para as camadas menos favorecidas em termos econômicos e, consequentemente, sociais do período vigente (SOFIATO, 2018).

Alguns pesquisadores do campo da Educação Especial já empreenderam pesquisas sobre o referido período, entre eles Rocha (2007), Soares (1999), Mazzotta (2001), Jannuzzi (2004), Sofiato (2011, 2018), entre outros. Entretanto, aprofundamentos em relação a alguns aspectos, tais como a escolarização dos surdos e a circulação da língua de sinais nesse contexto, ainda potencializam pesquisas.

A educação formal de surdos foi principiada no Brasil em 1857, com a fundação do Imperial Instituto dos Surdos-Mudos, por E. Huet, surdo e professor francês. Segundo Rocha (2007), Huet levou a cabo o projeto de estabelecimento de tal instituição com a anuência de D. Pedro II, que instituiu, desde o início, uma comissão inspetora para acompanhar o funcionamento do Instituto.

Por meio de estudos realizados por Sofiato (2018), constata-se que desde a fundação de tal estabelecimento foi delineada uma matriz curricular para o trabalho com os estudantes surdos, com disciplinas que envolviam diferentes áreas do conhecimento. Assumidamente oralista, o Imperial Instituto dos Surdos-Mudos prezava pelo desenvolvimento da linguagem oral dos estudantes por meio do oferecimento das disciplinas de articulação artificial e da leitura sobre os lábios. Tais disciplinas eram oferecidas para meninos e meninas, não determinando uma diferença de gênero para o ensino da fala e linguagem.

Diferentemente de outros colégios da época, que ofereciam o ensino de mais de uma língua, o Imperial Instituto dos Surdos-Mudos previa o ensino e o desenvolvimento de uma língua de forma oficial, ou seja, por meio de seu currículo prescrito, a língua portuguesa. No ano de 1868, verificamos que a língua francesa também foi cogitada para o ensino, mas não fez parte do currículo prescrito (BRASIL, 1868). Diante deste panorama e considerando-se que para o desenvolvimento do trabalho pedagógico com alunos surdos, muitas vezes, ocorre o uso de mais de uma língua, no caso, uma língua de modalidade espaço-visual, a pergunta que norteou a presente investigação foi a seguinte: houve a circulação de língua de sinais no Imperial Instituto dos Surdos-Mudos permeando o trabalho educacional? Tal questionamento se apresentou pertinente, mesmo se sabendo que, à época, a língua de sinais utilizada pelos surdos não tinha o status linguístico que possui hoje e que uma língua de sinais originalmente brasileira estaria por se constituir, na confluência dos sinais utilizados no Instituto com a língua francesa de sinais, língua que estabeleceu a nossa linhagem. 
Assim sendo, este estudo tem como objetivo compreender a educação de surdos no século XIX e como se dava a circulação da língua de sinais no Imperial Instituto de Surdos-Mudos, no referido período. Iniciaremos nossos estudos no ano de 1855, com a chegada de E. Huet ao Brasil (ROCHA, 2007), e percorreremos a trajetória dessa instituição até o ano de 1889, contemplando parte do período Imperial. Salientamos que a escolha por esse estabelecimento se deu devido à sua relevância histórica, às possibilidades de acesso a um corpus pouco explorado pela área e pelo tempo que essa instituição orientou a educação oferecida aos estudantes surdos em nível nacional.

A presente investigação possui uma abordagem qualitativa e se caracteriza como bibliográfica e documental. Gil (2002) pontua que a diferença entre a pesquisa bibliográfica e a documental está relacionada à natureza das fontes. Segundo o autor, a pesquisa bibliográfica é desenvolvida "com base em material já elaborado, constituído principalmente de livros e artigos científicos" (GIL, 2002, p. 44) e "a pesquisa documental vale-se de materiais que não recebem ainda um tratamento analítico, ou que ainda podem ser reelaborados de acordo com os objetos da pesquisa" (GIL, 2002, p. 45).

No estudo em questão, o corpus utilizado foi constituído por Relatórios dos Diretores do Imperial Instituto de Surdos-Mudos, Relatórios dos Ministros e Secretários de Estado dos Negócios do Império e cartas da época, ou seja, fontes primárias. Ademais, a análise do material encontrado referente ao período delineado, seguiu os pressupostos de Marson (1984), considerando os três níveis de indagação propostos pelo autor sobre os documentos, entre eles:

Sobre a existência em si do documento [...] o que é capaz de nos dizer, como podemos recuperar o sentido deste seu dizer, [...] quem o fez, em que circunstâncias e para que finalidade foi feito?; sobre o significado do documento como objeto [...] como e por quem foi produzido?, para que e para quem se fez essa produção?... e sobre o significado do documento como sujeito (por quem fala o documento? De que história particular participou? Que ação e que pensamento estão contidos em seu significado?) [...] em que consiste seu ato de poder? (MARSON, 1984, p. 52).

Tais questões nortearam as análises e circunscreveram núcleos de sentidos a partir dos quais pudemos constituir uma narrativa, em busca de algo mais original para o campo, considerando, também, contribuições pertinentes de outros autores no âmbito da pesquisa bibliográfica.

\section{A LÍNGUA DE SINAIS NO IMPERIAL INSTITUTO DE SURDOS-MUDOS}

A fundação do Imperial Instituto de Surdos-Mudos no Brasil foi um reflexo das discussões que fervilhavam no cenário mundial, mais especificamente no europeu, a respeito da educação dos surdos. Nesse contexto, Alemanha e França traziam duas grandes tendências na educação dos surdos e as questões relativas à surdez estavam ganhando destaque em todo o mundo. "A escola alemã representava o método oral e a escola francesa o método combinado"4 (ROCHA, 2007, p. 15), duas correntes distintas que permeiam há séculos as discussões sobre a comunicação dos surdos.

Soares (1999) afirma que a educação brasileira sofreu durante muito tempo influência do cenário educacional francês, apesar de, economicamente, não ter sido dependente desse país. Isso trouxe reflexos para educação dos surdos, que foi profundamente marcada por esta influência. Em alguns países do mundo já havia instituições que se dedicavam à educação de surdos desde o século XVIII. No Brasil, a primeira, como dito anteriormente, surgiu no século XIX. Segundo Rocha (2007), foi no ano de 1855 que o professor surdo E. Huet, do Instituto de Surdos de Paris, mostrou a intenção de estabelecer uma escola destinada ao ensino de surdos no território brasileiro.

Huet apresentou ao imperador do Brasil um documento que pedia ao governo ajuda para a instalação da primeira escola de surdos (ROCHA, 2007). Iniciou-se, naquele momento, o processo de

\footnotetext{
${ }^{4}$ Segundo Rocha (2007), a escola alemã era representada pelo pastor Samuel Heinicke, enquanto a francesa era representada pelo abade Charles Michel L'Epée. 
criação do Imperial Instituto dos Surdos-Mudos. Segundo Rocha (2007, p. 29-30), a princípio, o Instituto teve como proposta oferecer um curso que:

Tinha duração de seis anos, com foco no ensino agrícola, em função das características socioeconômicas do Brasil. Para as meninas, eram as mesmas regras, além do compromisso de organizar uma sociedade beneficente composta por senhoras notáveis.

E. Huet estabeleceu a primeira escola de surdos no ano de 1856, sendo que ela funcionou, provisoriamente, no prédio do Colégio Vassimon (MAZZOTA, 2001). Segundo dados do Almanak Laemmert (1856, p. 406), o objetivo da fundação do Instituto era a "regeneração intellectual e moral dos Surdos-Mudos do Brasil". Os objetivos da educação que se oferecia à época não eram muito distintos dos previstos para colégios de ouvintes. Por exemplo, para o Instituto Collegial de Nova Friburgo, a finalidade era "dar aos seus alumnos uma educação religiosa e moral, physica e intellectual" (ALMANAK, 1856, p. 402). No entanto, ao alunado surdo falava-se em "regeneração", enquanto aos ouvintes os termos utilizados eram de outra natureza. Vê-se que a concepção de surdo que se tinha à época era de um sujeito que precisava ser "regenerado", normalizado, para que então pudesse ser restituído e ter uma vida menos onerosa possível em sociedade.

De acordo com o material da série histórica do Instituto Nacional da Educação de Surdos, que traz a tese de doutorado de Bacellar (1926, p. 83), já no ano de 1856 "publicou Huet o seu Programa de Ensino, o qual comprhendia: lingua portugueza, arithmetica, geographia e historia do Brasil, escripturação mercantil, linguagem articulada e leitura sobre os labios (aos que tivessem aptidão) e doutrina christã".

A língua brasileira de sinais ainda estava longe de obter seu reconhecimento linguístico. Isso só se daria no século XXI, e não aparecia no programa educacional do Instituto por razões óbvias: em função do oralismo e por não ser considerada língua. Entretanto, queremos destacar a sua presença no cotidiano do colégio e as evidências de seu uso em algumas práticas escolares. Outra questão é que a língua brasileira de sinais, ao que tudo indica, ainda estava se constituindo no Brasil, na confluência com a língua francesa de sinais.

Segundo Rocha (2007), foi no dia 26 de setembro de $1857^{5}$ que Dom Pedro II, pela Lei $\mathrm{n}^{\circ}$ 839, garantiu um subsídio financeiro para a instituição e, então, foi oficializada a fundação do Instituto de Surdos e Mudos no Rio de Janeiro. Huet, fundador e proprietário do Instituto, tornou-se o primeiro diretor desse estabelecimento e ocupou o cargo no período de 1856 a 1861 (ROCHA, 2007). Segundo dados encontrados no Relatório Ministerial, referente ao ano de 1860, Huet demonstrou a intenção de deixar o cargo de diretor do Instituto (BRASIL, 1861). Porém, foi apenas no ano de 1861 que ele oficializou sua saída, garantindo que recebesse certa quantia em dinheiro como reconhecimento de seu trabalho (BRASIL, 1862).

Depois dele, nesses mais de 160 anos de história, muitos outros diretores foram responsáveis pela gestão do INES e, de alguma forma, contribuíram para a constituição do cenário educacional dos surdos no Brasil. Neste texto destacaremos alguns dos diretores do período imperial que marcaram de forma bastante pontual a história do Instituto e que, em suas gestões, encontramos indícios de circulação da língua de sinais no referido estabelecimento de ensino. Vale lembrar que, no período investigado (1855 a 1889), o Imperial Instituto dos Surdos-Mudos teve cinco diretores.

Com a saída de Huet, segundo Rocha (2007), o Instituto contou com a atuação de dois diretores no período de um ano. Então, em 1862:

Tendo vagado o lugar de director, espera o Governo, para o preencher effectivamente, que regresse de Pariz o seu pensionista Manoel de Magalhães Couto, o qual se tem applicado, no Instituto dos surdos-mudos daquella cidade, a instruir-se na linguagem dos surdos-mudos, a fim de habilitar-se para dirigir o nosso Instituto, e ao mesmo tempo encarregar-se do ensino (BRASIL, 1863, p. 28, grifo nosso).

\footnotetext{
${ }^{5}$ No dia 26 de setembro é comemorado o Dia Nacional do Surdo, segundo o Instituto Nacional de Educação de Surdos (INES, 2016). Mais informações no site: http://www.ines.gov.br. 
É interessante perceber que, apesar de não estar contida na documentação pedagógica do Instituto, a língua que os surdos usavam, chamada na época de linguagem dos surdos-mudos, é entendida como um requisito importante para aqueles que decidem atuar na educação de surdos. Ou seja, encontramos um indício relevante de que a língua de sinais permeava as relações estabelecidas no Instituto, provavelmente como uma forma de comunicação, ainda que em muitos momentos da história isso não seja evidenciado.

No que tange ao aspecto pedagógico, Sofiato (2018) aponta que havia um currículo prescrito no Imperial Instituto de Surdos-Mudos que era estabelecido nos meios oficiais e um currículo real, que, segundo Sacristán (1998), origina-se da relação entre o currículo manifesto e o currículo oculto. Pode-se dizer que a língua de sinais não se apresentava no currículo prescrito, no currículo oficial da instituição, mas ela estava presente em alguma medida no Instituto, nos processos pedagógicos.

No Relatório Ministerial do Império do ano de 1865, mais uma vez são apontadas as disciplinas curriculares que deveriam orientar o trabalho pedagógico. Eram elas: "a lingua nacional, arithmetica e algebra, historia e geographia, calligraphia, desenho, articulação artificial e leitura sobre os labios, accrescendo para as meninas trabalhos de agulha e de bordadura" (BRASIL, 1866, p. 19). Ainda nesse documento, há referência à necessidade do estabelecimento de oficinas para que os alunos fossem preparados para a vida prática. Segundo Sofiato (2018), esse caráter de ensino profissional, de educação para o trabalho, não era uma exclusividade das instituições que atendiam crianças e jovens com deficiência, esse era também um direcionamento comum na educação das classes menos favorecidas da sociedade imperial.

Vê-se que há, no trecho do Relatório Ministerial (BRASIL, 1866) em que são destacadas as disciplinas que orientam o trabalho pedagógico da instituição, algumas oficinas destinadas especificamente às meninas. Sofiato (2018, p. 221-222) problematiza essa diferenciação do ensino, pontuando que "as distinções curriculares imprimiam-se nas relações envolvendo gênero e à escola cabia fazer esse papel: a formação da mulher para a vida doméstica e a do homem para a vida pública". A autora, em sua análise, pondera que a fundação de instituições que atendessem a parcelas menos favorecidas da população fez parte de um projeto do Império para oferecer certo nível de escolaridade, de acordo com os interesses da ordem social e econômica daquele período histórico. O ensino de crianças das classes populares, de meninas, de surdos, de cegos e de crianças com outras deficiências não foi, portanto, algo despretensioso.

No ano de 1867 que foi atribuído ao Instituto o caráter de estabelecimento público (BRASIL, 1868). Segundo o Relatório Ministerial do Império de 1879,

Este Instituto conta 24 annos de existencia dividida em tres periodos bem distinctos: de 1856 a 1861 como empresa particular, de 1861 a 68 como estabelecimento subvencionado pelo Governo, sob a direcção de uma commissão composta dos homens mais eminentes do paiz, e de 1869 a 79 como estabelecimento publico de educação (BRASIL, 1880, p. A-E2-1).

No mesmo ano encontra-se a afirmação de que o Instituto fora criado com a finalidade de oferecer "educação intellectual, moral e religiosa aos surdos-mudos de ambos os sexos que se achassem nas condições de recebel-a" (BRASIL, 1868, p. 28). Para que o objetivo fosse alcançado, as disciplinas que compunham a matriz curricular do Instituto eram: "leitura, escripta, doutrina christã, arithmetica, geometria elementar e desenho linear, elementos de historia e geographia, sobretudo nacionaes, portuguez, francez e contabilidade". Observa-se que há menção à língua francesa no currículo prescrito pela primeira vez como língua estrangeira, mas não se considerava a "linguagem dos surdos-mudos" nem mesmo como um aporte para o ensino de línguas.

Assim como já citado, também no Relatório Ministerial de 1867 ressalta-se a importância do oferecimento de uma educação profissional aos alunos. No mesmo ano, com o Decreto 4.046 de 19 de dezembro de 1867, estabeleceu-se um Regulamento provisório para o Instituto (BRASIL, 1868). Dentre os diversos pontos discutidos nesse documento, salientamos a determinação da duração de cinco anos de curso oferecido, de modo que em cada ano os alunos tivessem acesso a determinadas 
matérias. Percebe-se que, na época, havia uma distinção entre os alunos que "demonstravam" ter uma aptidão maior para o ensino e aqueles que não a tinham. Os alunos com pouca aptidão para o estudo eram direcionados para trabalhos de ordem mais prática. (BRASIL, 1868).

Apesar de ter sido criado para atender às necessidades educacionais dos surdos, e de haver um Regulamento que estabelecia diversas disposições acerca de uma proposta pedagógica, uma inspeção feita no Instituto, no ano de 1868, demonstrou que este servia muito mais como um abrigo para seus frequentadores do que como uma instituição de ensino (ROCHA, 2007).

Considerações quanto à natureza do "ensino" que se oferecia aos surdos permearam as discussões sobre a educação desse alunado. Segundo Soares (1999), o trabalho com surdos sempre foi marcado pelo caráter assistencial e médico, ficando o ensino relegado a segundo plano. As primeiras iniciativas de educação vieram de médicos, que buscavam tratamentos para a surdez, e/ou estavam ligadas à caridade, eram "frutos da benevolência" (SOARES, 1999, p. 108) do homem - a motivação religiosa é bastante presente quando se fala em caridade. Esse caráter inicial parece ter sido mantido ao longo dos anos.

Segundo Rocha (2007), tendo em vista o não atendimento de uma proposta educacional constatada pela inspeção, o Dr. Tobias Rabello Leite assumiu a direção do Instituto após a exoneração do Dr. Manoel de Magalhães Couto, em 1868, ficando cerca de vinte e oito anos nesse cargo. Acompanhou, durante sua gestão, a mudança de regime político no Brasil (Império para República).

Logo no início da gestão, o Dr. Tobias Rabello Leite constatou a ineficiência do ensino que era oferecido no Instituto ao afirmar, no Relatório do Diretor do ano de 1868, que os alunos que estavam há pouco tempo no estabelecimento possuíam o mesmo grau de instrução daqueles que estavam estabelecidos há alguns anos (BRASIL, 1869), ou seja, não havia uma aprendizagem significativa daqueles que tinham acesso à educação no Imperial Instituto dos Surdos-Mudos.

Nesse Relatório, o diretor afirmava que não havia dificuldades para a educação dos surdosmudos $^{6}$. O Dr. Tobias Leite pontuava que "a educação do surdo-mudo depende hoje mais da caridade que da sciencia, pois nada mais exige do que a intelligencia, o methodo e a paciencia indispensaveis aos professores dos que ouvem e fallão" (BRASIL, 1869, p. A-D7-4). Ou seja, para o Dr. Tobias Leite bastava ser professor e ter caridade para educar o surdo-mudo.

Apesar desta afirmação, o Dr. Tobias Leite acreditava no oferecimento de uma educação que ensinasse aos surdos um ofício, de modo que eles pudessem ser (e sentir-se) úteis à sociedade. "Em sua opinião, o objetivo dos Institutos de Surdos não era o de formar homens de letras, mas ensiná-los uma linguagem que os habilitassem a manter relações sociais, tirando-os do isolamento provocado pela surdez" (ROCHA, 2007, p. 40).

Para viabilizar essa educação, Tobias Leite enfatizava que era necessário que o surdo tivesse acesso a uma linguagem escrita ou "vocal artificial" (BRASIL, 1869, p. A-D7-5). Dizia que a linguagem escrita atendia tanto a surdos congênitos como a surdos acidentais", sendo a linguagem "articulada artificial" mais viável aos surdos acidentais. Em alguns relatórios, dentre eles o Relatório Ministerial do ano de 1869 (BRASIL, 1870), o Dr. Tobias Leite afirmava que o ensino da linguagem escrita acontecia por meio do método intuitivo ${ }^{8}$. Vale salientar que esse método não era exclusivo para o ensino de surdos.

Verificando os relatórios apresentados ao longo da gestão do Dr. Tobias Leite, percebe-se que alguns pontos eram constantemente retomados pelo autor, dentre eles: a finalidade do Instituto quanto à formação de cidadãos úteis; a utilização do método intuitivo para o ensino; a dificuldade de implantação do ensino profissional, tão necessário para a formação de homens úteis; a importância da

\footnotetext{
6 Termo usado à época e que será utilizado em alguns momentos, quando a necessidade de marcação temporal existir. Atualmente, utiliza-se o termo "surdo" em decorrência dos estudos que encaram a surdez sob a perspectiva da diferença linguística.

${ }^{7}$ A surdez acidental, a qual se refere o diretor Dr. Tobias Leite, é a que atualmente chamamos de surdez adquirida.

${ }^{8}$ Segundo Saviani (2013, p. 138), a Reforma Leôncio de Carvalho aponta para a adoção do método intuitivo que vem com o objetivo de "resolver o problema da ineficiência do ensino". No método intuitivo, "o ensino deve partir de uma percepção sensível. O princípio da instituição exige o oferecimento de dados sensíveis à observação e à percepção do aluno" (REIS FILHO, 1995, p. 68 apud SAVIANI, 2013, p. 140).
} 
linguagem escrita para o ensino dos alunos surdos (BRASIL, 1871), pois considerava-se que ela era o único meio de expressão para esse alunado, entre outros apontamentos.

Apesar de discorrer sobre a linguagem escrita, em alguns momentos como a única forma de expressão, no Relatório Imperial do ano de 1870, um trecho dos escritos do diretor, ao descrever o "Estado Sanitário" do Instituto, nos permitiu encontrar mais um indício de circulação da língua de sinais nesse estabelecimento.

Uma circumstancia especial se dá no surdo-mudo, e é que qualquer alteração do seu estado physiologico tende a localizar-se mais ou menos no pulmão, si a surdo-mudez é congenita, no cérebro si é accidental. Ao medico que não tem habito de tratal-os, parece á primeira vista que graves lesões desses orgãos são a causa do que vêem, e não sabendo interrogal-os, nem traduzir a linguagem de signaes naturaes, embora n'essas occasiões ainda mais expressiva do que ordinariamente é, difficilmente póde formar um diagnostico seguro (BRASIL, 1871, p. A-E2-8, grifo nosso).

Notamos, por meio desse excerto, que, para o ensino, valorizava-se a linguagem escrita, no entanto, podemos inferir que a "linguagem de signaes naturaes" estava presente no cotidiano do Instituto e era a forma de comunicação utilizada pelos alunos do estabelecimento durante as interações sociais. Percebemos que a língua de sinais circulava, embora já tenhamos destacado que ela não era reconhecida e aceita no processo educacional do surdo.

No Relatório Ministerial do ano de 1871, encontramos uma mudança de pensamento do diretor Tobias Leite. Anteriormente, ele havia declarado que para educar surdos-mudos bastava ser professor. No entanto, após alguns anos exercendo sua função, ao que tudo indica, passou a pensar de maneira distinta.

As circumstancias peculiares do surdo-mudo requerem, tanto em seus professores como nas pessoas incumbidas de vellarem sobre elle e dirigir-lhe a educação, habilitações e habitos especiaes, que se não adquirem sem estudos proprios e longa experiencia (BRASIL, 1872, p. 72).

A vivência como diretor pode ter feito o Dr. Tobias Leite perceber algumas especificidades de seu alunado. Retomando aspectos já apontados pelo diretor, no Relatório Imperial fica explícita a educação que se deveria oferecer ao surdo-mudo: uma educação de caráter "prático e real" (BRASIL, 1872 - p. 74). Segundo o mesmo Relatório, um surdo-mudo sem instrução seria um fardo e uma ameaça para a sociedade (BRASIL, 1872).

Em todos os Relatórios estudados percebe-se que a linguagem escrita era enaltecida e havia também menção à linguagem articulada. No entanto, encontramos referência à mimica no Relatório do ano de 1872, na seção chamada Instruç̧ão.

O modo de ensinar a linguagem escripta e a mimica póde-se aprender lendo os compendios, e estudando as estampas, e effectivamente os Professores do Instituto assim se habilitaram; mas a linguagem articulada não é possível sinão vendo praticar, pela razão muito simples de que os sons da lingua franceza e da allemã, em que se acham escriptos os compendios, e compostas as estampas, são differentes dos da lingua portuguesa (BRASIL, 1873, p. A-C3-5, grifo nosso).

Analisando o excerto, pode-se inferir que a mimica era a língua de sinais e, mais do que presente nas interações entre os alunos, ela era fonte de estudo dos professores que ali atuavam, pois se afirmava que a mimica poderia ser aprendida por meio das leituras de estampas. Esse fato nos remete às possíveis consultas feitas por professores que atuavam no instituto a materiais com estampas de outras línguas de sinais (possivelmente franceses), já que, naquele tempo, no Brasil não havia recursos de tal natureza, afinal, o primeiro material de que se tem notícia só seria publicado em 1875 (SOFIATO, 2011). 
No Relatório Ministerial do ano de 1873 constava que "em virtude da autorização conferida no art. $2^{\circ}$ da Lei $n^{\circ} 2318$ de 25 de agosto do anno findo, foi expedido o Decreto ${ }^{\circ} 5135^{9}$ de 15 de outubro, que deu nova e definitiva organização a este Instituto" (BRASIL, 1874, p. 63). Com essas alterações e com o objetivo de enfatizar o ensino profissional, foram reduzidas as disciplinas do Instituto, ficando apenas "lingua portuguesa, arithmetica com suas aptidões práticas, elementos de geometria e agrimensura, geographia e historia do Brazil" (BRASIL, 1874, p. 63). Além disso, a oficina de sapateiro já estava estabelecida e estava encaminhada a oficina de encadernação. O diretor Tobias Leite defendia que seria fundamental aos surdos terem acesso às oficinas relacionadas à agricultura.

Ainda nesse relatório, uma observação feita por Tobias Leite chamou a atenção, pois esse afirmava que no ensino de língua portuguesa seria importante que se preservasse a ordem natural das frases no momento de sua composição. Além disso, salientava que se deveria evitar o uso de figuras para o ensino dos estudantes surdos (BRASIL, 1874). Refletindo sobre a primeira ideia do diretor, pode-se pensar que a ênfase na preservação da ordem natural das frases estivesse relacionada a alguma dificuldade apresentada pelos estudantes surdos em suas composições, devido à influência da língua de sinais, em processos de interlíngua, ou seja, na confluência da língua portuguesa com a língua de sinais. A circulação da língua de sinais dentro do Instituto nem sempre aparecia explicitamente nos Relatórios, no entanto, indícios marcam o território de tal língua na educação dos surdos no período delineado para o estudo.

Apesar da importância da língua portuguesa para o desenvolvimento do aluno surdo, o Dr. Tobias Leite parece ter aceitado o uso dos sinais pelos surdos do Instituto, já que, além de encontrarmos, nos Relatórios Imperiais, indícios de circulação dessa língua no referido estabelecimento, no ano de 1875 foi publicada a Iconographia dos signaes dos surdos-mudos, importante obra para o estudo em questão.

Segundo Tobias Leite, a publicação da Iconografia teve dois fins específicos:

$1^{\circ}$ Vulgarisar a linguagem dos signaes, meio predilecto dos surdos-mudos para a manifestação dos seus pensamentos. Os pais, os professores primarios, e todos os que se interessarem por esses infelizes, ficaráõ habilitados para os entender e se fazerem entender. $2^{\circ}$ Mostrar o quanto deve ser apreciado um surdo-mudo educado (GAMA, 1875, p.12).

Diversos pontos podem ser analisados a partir desse excerto. O primeiro é que o Dr. Tobias Leite reconheceu a "linguagem dos signaes" (GAMA, p. 12) como meio predileto de comunicação dos surdos, ou seja, inferimos que, além de estar presente no Instituto, a comunicação dos surdos por meio da língua de sinais era a mais efetiva e a predileta, porque era natural. Outro ponto é que se o dicionário foi publicado com o intuito de vulgarizar/divulgar a "linguagem dos signaes" (GAMA, p. 12), os sinais não eram proibidos naquele estabelecimento de ensino, mas também não eram "reconhecidos" no processo educacional do surdo, tendo em vista que não faziam parte do currículo.

Finalmente, por meio da publicação da referida obra, percebemos que havia uma preocupação com a divulgação do léxico da língua de sinais. Embora não tenhamos aqui um indício mais preciso de circulação dessa língua na época do Império, temos uma possível evidência de sua importância e a necessidade de seu registro. Sofiato (2011, p. 55) aponta que o diretor Tobias Leite apoiou a publicação da Iconographia dos signaes dos surdos-mudos, produzida por Flausino da Gama, já que esta obra "daria visibilidade ao trabalho desenvolvido no Instituto e nada melhor que um aluno, educado nesse estabelecimento, no papel de autor/produtor".

Além dos pontos destacados anteriormente, que nos fazem refletir sobre a publicação da Iconografia dos signaes dos surdos-mudos, Sofiato faz uma ressalva a respeito do aluno e repetidor Flausino da Gama que, apesar de ter reproduzido uma obra já existente, deve ser reconhecido como "um surdo que teve importante papel na propagação da língua brasileira de sinais, com a primeira tentativa de registro

\footnotetext{
${ }^{9}$ Não temos certeza em relação ao número do Decreto, pois a consulta foi realizada em uma fonte primária mal conservada, que dificultou a nossa leitura.
} 
há cento e trinta e seis anos atrás" (SOFIATO, 2011, p. 137). Isso nos leva a pensar que a busca pelo registro da língua de sinais era uma forma de valorizá-la e de conferir a nacionalidade brasileira a ela.

Ao estudar os Relatórios Imperiais de 1876, 1877, 1878 e 1879, deparamo-nos com fatos marcantes, que não tratavam especificamente do uso da língua de sinais pelos alunos do Instituto, mas que tiveram relação com a educação de surdos. Elencamos os acontecimentos mais relevantes deste período sem, no entanto, explorar detalhadamente cada um deles.

Constatou-se no ano de 1876: o aumento significativo do número de alunos do Instituto, a mudança do prédio para a Rua das Laranjeiras, a necessidade de ampliar o tempo de curso no Instituto para melhoria do ensino, a dificuldade em encontrar um professor para a cadeira de linguagem articulada e, em relação ao ensino profissional, o funcionamento de duas oficinas (de sapateiro e de encadernador), além do incentivo aos trabalhos agrícolas que os alunos desempenhavam durante as manhãs (BRASIL, 1877).

O ano de 1877, além da exoneração do repetidor Flausino da Gama, justificada por motivo de enlouquecimento, foi marcado: pela ênfase no direito constitucional do surdo à instrução, pela luta pelo provento da cadeira de $5^{\circ}$ e $6^{\circ}$ anos que permanecia vaga, pela finalidade da educação prática (foram sugeridas novas oficinas). Além disso, permanecia vaga a cadeira de linguagem articulada (BRASIL, 1878).

Já no ano de 1878 houve uma expressiva discussão acerca da instrução. Dentre os temas discutidos tem-se: os saberes que um aluno do $5^{\circ}$ ano de instrução deveria ter adquirido; o tempo de aprendizagem do surdo variando de acordo com "as intelligencias, os methodos, e o zelo dos professores" (BRASIL, 1879, p. A-B1-3), assim como acontece com os falantes; a carência do preenchimento das cadeiras do $5^{\circ}$ e $6^{\circ}$ ano e, também, da de linguagem articulada, entre outros. Houve grande destaque para a criação de um museu escolar e, também, para o ensino profissional, setor que o diretor Tobias Leite muito valorizava.

Por fim, no ano de 1879 ganhou força a luta pelo reconhecimento da eficiência da instrução dos surdos-mudos mediante a sociedade. Para a garantia de uma instrução com status de "perfeição", o Dr. Tobias Leite defendia ainda a presença dos repetidores e a ocupação das cadeiras de $5^{\circ}$ e $6^{\circ}$ anos e de linguagem articulada (BRASIL, 1880, p. A-E2-4). Foi então que, na gestão do Dr. Tobias Leite, aconteceu na Itália, em 1880, o Congresso de Milão. Este teve grande repercussão no campo da surdez, pois estabelecia a superioridade do método oral em relação ao uso da língua de sinais (SOARES, 1999).

O Brasil, assim como outros países, também sofreu o impacto do Congresso de Milão e, no Relatório Imperial de 1881, novamente destacaram-se as disciplinas oferecidas no estabelecimento supracitado. Eram elas: "lingua portuguesa, por meio da escripta, arithmetica, em suas aplicações communs, e noções geraes de geographia e historia do Brazil" (BRASIL, 1882a, p.99). Em outros Relatórios, como nos já citados, havia uma solicitação para o preenchimento da cadeira de linguagem articulada, mas, no Relatório do ano de 1881, essa solicitação aparece com caráter de urgência, talvez como um reflexo do direcionamento para a educação de surdos apontado no Congresso de Milão.

Nesse Relatório também foi aprovado um novo Regimento Interno para o Instituto dos surdos-mudos. Nele estavam dispostas considerações sobre os cargos e as funções, sobre o serviço sanitário do estabelecimento, sobre os regimes disciplinar e econômico, entre outras disposições (BRASIL, 1882a). No entanto, chama-nos a atenção um trecho do Regimento em que fica bastante claro que a surdo-mudez era compreendida numa perspectiva médica. No excerto que trata das atribuições do médico do Instituto, aparece como uma de suas funções:

$4^{\circ}$ Apresentar no fim do anno ao Director um relatorio circumstanciado do movimento sanitario, acompanhado de observações que sirvam ao estudo da surdo-mudez, e dos meios de attenuar seus effeitos (BRASIL, 1882a, A-E-4).

O tema da surdez estava alocado na seção do serviço sanitário, mesma seção responsável por cuidar de relatórios de enfermaria, dos alunos doentes, das atribuições do médico e do roupeiro (quando ele realizava a função de enfermeiro). Isso denota a concepção de surdez à época. Ainda no 
ano de 1881, afirmava-se que o governo aproveitou a ida do Dr. Joaquim José de Menezes Vieira à Europa para que ele estudasse os métodos de ensino de linguagem articulada utilizados nos países europeus (BRASIL, 1882b).

No ano de 1882, o Dr. Menezes Vieira retornou ao Brasil e assumiu a cadeira de linguagem articulada no Instituto. Segundo o Relatório do ano de 1882 (BRASIL, 1883), foi determinado pelo diretor Dr. Tobias Leite que a aula de linguagem articulada seria frequentada por apenas um número limitado de alunos e que eles ficariam separados dos demais estudantes do Instituto.

Refletindo sobre essa atitude do diretor, ficamos com algumas inquietações. Qual era o objetivo da separação dos alunos que frequentavam a aula de linguagem articulada daqueles que não a frequentavam? A língua de sinais permeava o Instituto e, por isso, não poderia haver contato entre os estudantes? O Dr. Tobias Leite entendia, assim como diversos contemporâneos seus ${ }^{10}$, que os sinais atrapalhariam o desenvolvimento da linguagem articulada?

Essas indagações também nos levaram a pensar que tipo de concepção estava norteando as decisões tomadas pelo diretor. A tensão entre o método oral e uso da língua de sinais estava presente também no Instituto dos Surdos-mudos do Brasil.

Em pesquisa no acervo da Biblioteca Nacional, sediada no Rio de Janeiro, encontramos uma carta do Dr. Tobias Leite ao Imperador tratando da educação dos surdos-mudos. Nesse documento encontra-se também a carta que o diretor recebeu de Lopes Netto, contando sobre a instrução dos surdos-mudos em Washington. Essas cartas datam do ano de 1883. O Dr. Tobias Leite justificou a busca de conhecimento nos Estados Unidos devido à tradição científica que eles tinham em relação ao público surdo.

O Dr. Tobias Leite elaborou alguns quesitos (questionamentos) que foram respondidos por Lopes Netto. A preocupação com o melhor método para o ensino dos surdos-mudos estava presente em toda a carta. Ao perguntar sobre o uso da palavra articulada e da palavra escrita, recebeu como resposta que todos os métodos poderiam ser usados para ensinar os surdos-mudos e que se deveria escolher o mais apropriado. Lopes Netto afirmou que alguns estabelecimentos optaram por utilizar um método misto, com uso de palavra escrita e articulada, e que alguns alunos utilizavam até mesmo os sinais pantomímicos (LEITE, 1883).

Leite (1883) perguntou sobre a utilização e/ou proibição do uso de sinais na educação de surdos. As respostas obtidas apontavam para um melhor desenvolvimento dos alunos que utilizam os sinais junto com as palavras. Com esses exemplos encontrados em uma documentação manuscrita, percebe-se que a língua de sinais fazia parte da comunicação e até mesmo do currículo oculto da educação que se oferecia aos surdos no Instituto de Surdos-Mudos do Brasil, como também de outros colégios e instituições de surdos pelo mundo, mesmo após o Congresso de Milão. Ao perguntar diversas vezes sobre o uso dos sinais, o Dr. Tobias Leite leva-nos a pensar que a recorrência e a influência deles na educação dos surdos-mudos era bastante expressiva. E, pela publicação da Iconographia dos signaes dos surdos-mudos durante a sua gestão, infere-se que ele possivelmente acreditava no uso da língua de sinais para a comunicação efetiva com os surdos.

No ano de 1886, ainda na gestão do Dr. Tobias Leite e em um contexto pós Congresso de Milão, o Dr. Joaquim José de Menezes Vieira ofereceu ao instituto 25 exemplares de sua obra didática A imagem e a palavra (BRASIL, 1887). Vê-se um investimento pontual na questão da instrução da linguagem articulada ao surdo-mudo. Ainda no ano de 1886, foi afirmado no Relatório Imperial que havia, internacionalmente, um cenário de incertezas em relação ao melhor método para o ensino dos surdos-mudos.

\footnotetext{
No tocante a este ramo do serviço agita-se em differentes paizes importante questão a que não podemos ser indifferentes, qual é a do melhor methodo que convem adoptar no ensino - si o mímico, si o oral, si o methodo mixto (BRASIL, 1887, p. 64).
}

\footnotetext{
10 Os defensores do método oral tinham como justificativa para a proibição dos sinais a concepção de que "tal prática atrapalharia o aprendizado da língua na modalidade oral" (SÁ, 1999, p. 76). 
Os debates acerca do método a ser utilizado para a instrução dos surdos sempre estiveram presentes, ilustraram-se com as diferenças de pensamento do francês abade Charles Michel L'Épée e do alemão Samuel Heinicke desde o século XVIII, e que se estenderam aos séculos subsequentes. O Imperial Instituto de Surdos-mudos não ficou alheio a isso e teve sua atuação influenciada pelo cenário internacional.

Até o ano de 1889, fim do período Imperial, não houve nenhum outro fato determinante que alterasse os rumos do encaminhamento pedagógico da educação de surdos. Entretanto, sabe-se que o fortalecimento da abordagem oralista se deu a partir do advento da República e se expandiu nos anos subsequentes no Instituto. Em que pese a força da abordagem oralista na educação de surdos enquanto uma tendência mundial e, consequentemente nacional, observa-se que a língua de sinais continuou presente na vida escolar dos surdos de forma marginal, mesmo com toda a força opressiva para a sua descontinuação.

\section{CONSIDERAÇÕES FINAIS}

A investigação realizada objetivou apresentar o desenvolvimento da educação de surdos, ao longo da segunda metade do século XIX no Brasil, e os indícios da presença da língua de sinais nos processos pedagógicos e no cotidiano do Imperial Instituto dos Surdos-Mudos. Apesar da dificuldade relacionada à busca das fontes e refinamento dos conteúdos encontrados, logrou-se construir uma narrativa para elucidar como a língua de sinais perpassava o processo educativo do surdo brasileiro no século XIX.

Por meio do estudo realizado, verificamos a importância que a língua portuguesa, na sua modalidade oral e escrita, teve para o desenvolvimento dos alunos surdos, demonstrada no currículo prescrito do Imperial Instituto dos Surdos-Mudos e predominando como única língua a ser trabalhada, apesar da inserção de outras línguas (estrangeiras) nos currículos escolares de outras escolas no Império, no caso, escolas para ouvintes. Não obstante, o Imperial Instituto dos Surdos-Mudos procurava seguir os princípios da educação geral, propostos em Leis do Império.

Em que pese o fato de o Imperial Instituto dos Surdos-Mudos ter assentado o seu trabalho pedagógico numa base oralista, antes e depois do Congresso de Milão, percebemos que ocorria a circulação da língua de sinais, mesmo não abarcando o status de língua e com todas as contraindicações a respeito de seu uso. Tal língua, ao que tudo indica, estava presente nas relações sociais entre os alunos, professores e funcionários do Instituto, nas práticas pedagógicas, nos materiais didáticos, e a importância de sua divulgação foi comprovada por meio da publicação da Iconographia dos Signaes dos Surdos-Mudos, de Flausino da Gama, em 1875. Além disso, a publicação de tal obra foi um importante marco para a constituição de uma língua de sinais nacional e para a sua difusão, apesar de ter sido espelhada na obra de 1856, de Pierre Pélissier, surdo francês.

Embora a língua portuguesa fosse considerada a língua a ser ensinada para o surdo brasileiro no contexto escolar, o estudo também mostrou as inquietações do diretor Dr. Tobias Rabello Leite quanto a escolha dos melhores métodos a serem utilizados, questionando até a pertinência do uso da língua de sinais, juntamente com a linguagem escrita. Faz-se mister lembrar que o método intuitivo era utilizado também na educação de surdos, seguindo uma tendência nacional, mas o seu desenvolvimento, nesse caso específico, ainda necessita ser mais bem precisado.

Diante do delineamento acerca da língua de sinais no século XIX, no Imperial Instituto dos Surdos-Mudos, podemos inferir que, mesmo utilizada de maneira informal e sem o status de língua que possui hoje, esteve presente quando as bases da educação de surdos estavam sendo constituídas no Brasil, apesar do fatídico desfecho do Congresso de Milão, em 1880. Tal afirmação se legitima quando observamos a sua utilização da primeira década do século XX em diante no Instituto, de forma peculiar, mas contundente, como mais uma estratégia para se chegar ao objetivo maior: o de fazer o surdo falar! 


\section{REFERÊNCIAS}

ALMANAK Laemmert (1844-1889). In: Center for Research Libraries. Global Resources Network. Disponível em: <http://www-apps.crl.edu/brazil/almanak>. Acesso em: 17 jun. 2018.

BACELLAR, Arnaldo de Oliveira. A surdo mudez no Brasil (cadeira de hygiene). Tese de doutoramento em Medicina de Arnaldo de Oliveira Bacellar, pela Faculdade de Medicina de São Paulo, em 1926. (Série Histórica do Instituto Nacional de Educação de Surdos; 6. Rio de Janeiro: INES, 2013).

BRASIL. Ministerio do Imperio. Ministro (Jose Antonio Saraiva). Relatorio do anno de 1860 apresentado a Assemblea Geral Legislativa na $1^{a}$ sessão da $11^{a}$ Legislatura. (Publicado em 1861). Disponível em: <http://brazil.crl.edu/bsd/bsd/u1733/>. Acesso em: 17 out. 2016.

BRASIL. Ministerio do Imperio. Ministro (Jose Idelfonso de Souza Ramos). Relatorio do anno de 1861 apresentado a Assemblea Geral Legislativa na $2^{a}$ sessão da $11^{a}$ Legislatura. (Publicado em 1862). Disponível em: <http://brazil.crl.edu/bsd/bsd/u1734/>. Acesso em: 17 out. 2016.

BRASIL. Ministerio do Imperio. Ministro (Pedro de Araujo Lima). Relatorio do anno de 1862 que se devia apresentar a Assemblea Geral Legislativa na $3^{\text {a }}$ sessão da $11^{a}$ Legislatura. (Publicado em 1863). Disponível em: < http://brazil.crl.edu/bsd/bsd/u1735>. Acesso em: 17 out. 2016.

BRASIL. Ministerio do Imperio. Ministro (Pedro de Araujo Lima). Relatorio do anno de 1865 apresentado à Assemblea Geral Legislativa na 4a sessão da 12a Legislatura. (Publicado em 1866). Disponível em: <http://brazil.crl.edu/bsd/bsd/u1740>. Acesso em: 17 out. 2016.

BRASIL. Ministerio do Imperio. Ministro (Jose Joaquim Fernandes Torres). Relatorio do anno de 1867 apresentado a Assemblea Geral Legislativa na $2^{\text {a }}$ sessão da $13^{a}$ Legislatura. (Publicado em 1868). Disponível em: <http://brazil.crl.edu/bsd/bsd/u1694/>. Acesso em: 17 out. 2016.

BRASIL. Ministerio do Imperio. Ministro (Paulino Jose Soares de Souza). Relatorio do anno de 1868 apresentado a Assemblea Geral Legislativa na $\mathbf{1}^{\mathbf{a}}$ sessão da $14^{\mathrm{a}}$ Legislatura. (Publicado em 1869). Disponível em: <http://brazil.crl.edu/bsd/bsd/u1695/>. Acesso em: 17 out. 2016.

BRASIL. Ministerio do Imperio. Ministro (Paulino Jose Soares de Souza). Relatorio do anno de 1869 apresentado a Assemblea Geral Legislativa na $2^{a}$ sessão da $14^{a}$ Legislatura. (Publicado em 1870). Disponível em: <http://brazil.crl.edu/bsd/bsd/u1696/>. Acesso em: 17 out. 2016.

BRASIL. Ministério do Império. Ministro (João Alfredo Corrêa de Oliveira). Relatorio do anno de 1870 apresentado á Assemblea Geral Legislativa na $3^{\mathrm{a}}$ sessão da $14^{\mathrm{a}}$ Legislatura. (Publicado em 1871). Disponível em: < http://brazil.crl.edu/bsd/bsd/u1697>. Acesso em: 17 out. 2016.

BRASIL. Ministerio do Imperio. Ministro (João Alfredo Corrêa de Oliveira). Relatorio do anno de 1871 apresentado a Assemblea Geral Legislativa na $4^{\text {a }}$ sessão da $14^{a}$ Legislatura. (Publicado em 1872). Disponível em: < http://brazil.crl.edu/bsd/bsd/u1698/> . Acesso em: 17 out. 2016.

BRASIL. Ministerio do Imperio. Ministro (João Alfredo Corrêa de Oliveira). Relatório do anno de 1872 apresentado a Assemblea Geral Legislativa na $2^{a}$ sessão da $15^{a}$ Legislatura. (Publicado em 1873). Disponível em: <http://brazil.crl.edu/bsd/bsd/u1700/>. Acesso em: 17 out. 2016. 
BRASIL. Ministerio do Imperio. Ministro (João Alfredo Corrêa de Oliveira). Relatório do anno de 1873 apresentado a Assemblea Geral Legislativa na $3^{\text {a }}$ sessão da $15^{\text {a }}$ Legislatura. (Publicado em 1874). Disponível em: http://brazil.crl.edu/bsd/bsd/u1701. Acesso em: 17 Out. 2016.

BRASIL. Ministerio do Imperio. Ministro (José Bento da Cunha e Figueiredo). Relatório do anno de 1876 apresentado a Assemblea Geral Legislativa na 1 ${ }^{\text {a }}$ sessão da $16^{\text {a }}$ Legislatura. (Publicado em 1877). Disponível em: <http://brazil.crl.edu/bsd/bsd/u1742/>. Acesso em: 17 out. 2016.

BRASIL. Ministerio do Imperio. Ministro (Carlos Leoncio de Carvalho). Relatorio do anno de 1877 apresentado a Assemblea Geral Legislativa na $1^{a}$ sessão da $17^{a}$ Legislatura. (Publicado em 1878). Disponível em: <http://brazil.crl.edu/bsd/bsd/u1744/>. Acesso em: 17 out. 2016.

BRASIL. Ministerio do Imperio. Ministro (Carlos Leoncio de Carvalho). Relatorio do anno de 1878 apresentado a Assemblea Geral Legislativa na $2^{a}$ sessão da $17^{a}$ Legislatura. (Publicado em 1879). Disponível em: <http://brazil.crl.edu/bsd/bsd/u1745/>. Acesso em: 17 out. 2016.

BRASIL. Ministerio do Imperio. Ministro (Francisco Ignacio Marcondes Homem de Mello). Relatorio do anno de 1879 apresentado a Assemblea Geral Legislativa na $3^{a}$ sessão da $17^{a}$ Legislatura. (Publicado em 1880). Disponível em: <http://brazil.crl.edu/bsd/bsd/u1746>. Acesso em: 17 out. 2016.

BRASIL. Ministerio do Imperio. Ministro (Manoel Pinto de Souza Dantas). Relatorio do anno de 1881 apresentado a Assemblea Geral Legislativa na $1^{\text {a }}$ sessão da $18^{a}$ Legislatura. (Publicado em 1882a). Disponível em: <http://brazil.crl.edu/bsd/bsd/u1747>. Acesso em: 17 out. 2016.

BRASIL. Ministerio do Imperio. Ministro (Rodolpho Epiphanio de Souza Dantas). Relatorio do anno de 1881 apresentado a Assemblea Geral Legislativa na $2^{a}$ sessão da $18^{a}$ Legislatura. (Publicado em 1882b). Disponível em: <http://brazil.crl.edu/bsd/bsd/u1748/>. Acesso em: 17 out. 2016.

BRASIL. Ministerio do Imperio. Ministro (Pedro Leão Velloso). Relatorio do anno de 1882 apresentado a Assemblea Geral Legislativa na $3^{a}$ sessão da $18^{a}$ Legislatura. (Publicado em 1883). Disponível em: http://brazil.crl.edu/bsd/bsd/u1749/. Acesso em: 17 out. 2016.

BRASIL. Ministerio do Imperio. Ministro (Ambrosio Leitão da Cunha). Relatorio do anno de 1886 apresentado a Assemblea Geral Legislativa na $2^{a}$ sessão da $20^{a}$ Legislatura. (Publicado em 1887). Disponível em: <http://brazil.crl.edu/bsd/bsd/u1372/>. Acesso em: 17 out. 2016.

GAMA, Flausino José da. Iconographia dos signaes dos surdos-mudos. Rio de Janeiro: Typographia Universal de E. \& H. Laemmert, 1875. (Série Histórica do Instituto Nacional de Educação de Surdos; 1. Rio de Janeiro: INES, 2011).

GIL, Antônio Carlos. Como elaborar projetos de pesquisa. São Paulo: Atlas, 2002.

INES, Instituto Nacional de Educação de Surdos. Disponível em: <http://www.ines.gov.br>. Acesso em: 5 dez. 2016.

JANNUZZI, Gilberta de Martino. A educação do deficiente no Brasil: dos primórdios ao início do século XIX. Campinas, SP: Autores Associados, 2004. 
LEITE, Tobias Rabello. Carta a [D. Pedro II] tratando da educação de surdos-mudos e remetendo carta de Lopes Netto que versa os estudos sobre este assunto realizados por Gallaudet. Rio de Janeiro: [s.n.], 02/04/1883. (Acervo da Biblioteca Nacional).

MARSON, Adalberto. Reflexões sobre o procedimento histórico. In: SILVA, Marco A. da (Org.). Repensando a história. Rio de Janeiro: Marco Zero, 1984, p. 37-64.

MAZZOTTA, Marcos José Silveira. Educação Especial no Brasil: História e políticas públicas. 3. ed. São Paulo: Cortez, 2001.

ROCHA, Solange. O INES e a Educação de Surdos no Brasil. Rio de Janeiro: INES, 2007.

SÁ, Nídia Regina Limeira de. Educação de Surdos: a caminho do bilinguismo. Niterói: EdUFF, 1999.

SACRISTÁN, J. Gimeno. O currículo: os conteúdos do ensino ou uma análise prática? In: SACRISTÁN, J. Gimeno; GÓMEZ, A. I. Pérez. Compreender e transformar o ensino. Trad. Ernani F. da Fonseca Rosa - 4. ed. - ArtMed, 1998, p. 119-148.

SAVIANI, Dermeval. História das ideias pedagógicas no Brasil. 4. ed. Campinas, SP: Autores Associados, 2013. - (Coleção memória da educação).

SOARES, Maria Aparecida Leite. A educação do surdo no Brasil. Campinas, SP: Autores Associados; Bragança Paulista, SP: EDUSF, 1999.

SOFIATO, Cássia Geciauskas Sofiato. Do desenho à litografia: a origem da língua brasileira de sinais. 2011. 265f. Tese (Doutorado) - Universidade Estadual de Campinas, Instituto de Artes - Campinas, SP: $\quad$ [s.n.], $2011 . \quad$ Disponível em: <http://www.bibliotecadigital.unicamp.br/document/?code $=000796432 \& \mathrm{fd}=\mathrm{y}>$. Acesso em: $15 \mathrm{dez}$. 2016.

SOFIATO, Cássia Geciauskas. A educação de surdos no século XIX: currículo prescrito e modelo de educação. Cad. Pesq., São Luís, v. 25, n. 2, p.207-224, abr. 2018. Disponível em: <http://www.periodicoseletronicos.ufma.br/index.php/cadernosdepesquisa/article/view/9329/5544 >. Acesso em: 09 jul. 2018. 